\title{
Comparative Study of Mucositis in Patients of Head and Neck Cancer Treated by External Radiotherapy with or Without Amifostine.
}

\author{
K. Al-Saleh ${ }^{1}$, H. Elwakiel ${ }^{2}$, R. Safwat ${ }^{3}$ and A. Gaber ${ }^{4}$ \\ ${ }^{1}$ Department of Radiation Oncology, K.C.C.C, ${ }^{2}$ Department of Radiation Oncology, Ain Shams \\ University, ${ }^{3}$ Department of Radiation Oncology, zagazig University, ${ }^{4}$ Department of Medical Physics, \\ Alexandria University ${ }^{4}$.
}

\begin{abstract}
Amifostine is an organic thiophosphate that has been evaluated for protection from toxicities of radiotherapy. This retrospective study assessed the influence of amifostine on mucositis in patients with head and neck cancer that underwent radiotherapy at the Kuwait Cancer Control Center. Between October 2004 and May 2007, thirty-five patients were given amifostine $500 \mathrm{mg}$ subcutaneously 1520 minutes daily before radiotherapy. Toxicities were compared to those of a control group $(n=35)$ that did not receive amifostine. Mucositis was less common in the amifostine group than the control group (71.4\% vs $97.1 \%, P=.008)$. Nausea/vomiting $(45.7 \%$ vs $14.3 \%, P=.004)$ and asthenia $(45.7 \%$ vs $14.3 \%, P=.004)$ were more common in the amifostine group than the placebo group. Three $(8.6 \%)$ patients in the amifostine group developed skin rash, including two localized reactions. Long term follow up is needed to confirm the protective effect and safety of subcutaneous amifostine against mucositis in patients with head and neck cancer.
\end{abstract}

Key words: Amifostine, Mucositis, Head and Neck Cancer, Radiotherapy.

Corresponding Author: H. Elwakiel_ E-mail: hasham_elwekel@yahoo.com

\section{INTRODUCTION}

Head and neck malignancies constitute $5 \%$ of all cancers worldwide and they are more common in men than in women ${ }^{1,2}$. More than 42.000 new cases of head and neck squamous cell carcinoma occur in the United States every year ${ }^{3}$. In Kuwait, they are also among the most common malignancies. Cancer of the head and neck region impairs many activities of daily life such as chewing, speaking and swallowing.

Patients with locally advanced head and neck cancer are frequently treated with concurrent chemoradiotherapy ${ }^{4}$.

Radiotherapy is the mainstay of treatment of head and neck cancer, but it usually causes mucositis and xerostomia, which may exacerbate the existing problems. Since mucositis represents the dose-limiting acute toxicity and xerostomia ranks as the most common long-term quality-of-life complaint, radiation dose cannot be increased without increasing the toxicity, thus compromising local control and survival. In an effort to overcome this problem, amifostine (Ethyol) has been used in various studies with encouraging results in patients with head and neck cancer ${ }^{5-10}$.

Amifostine is a radio-protective agent that scavenges radiation-induced free radicals and has been shown to protect normal tissues from adverse effects of radiation in various experimental models. It is rapidly dephosphorylated and enters cells as a metabolite, WR1065. Its plasma clearance is rapid and its elimination is essentially urinary ${ }^{11}$.

Amifostine was discovered by the US army in 1950s under the name of WR-2721. It is metabolized by membrane-bound alkaline phosphatase. Theoretically, its protective effect is selective for normal cells because of decreased levels of membrane-bound alkaline phposphatase in neoplastic cells where acidic $\mathrm{pH}$ downregulates the alkaline phosphatase activity. In fact, it may enhance the anti-neoplastic activity of RT and/ or chemotherapy by either increasing the intensity of treatment or avoiding unnecessary interruptions during radiotherapy ${ }^{12}$. Other mechanism of preferential protection of the normal tissues includes increased uptake of the compound by certain organs such as salivary glands and kidneys ${ }^{13}$.

The half-life of amifostine ranges from 1 to 3 minutes and follows a dose-dependent clearance consistent with saturable kinetics, which is probably related to capacitylimited metabolism by alkaline phosphatase, the key enzyme for the dephosphorylation of WR-2721 to its 
active metabolite, WR $1065^{14}$. All normal tissues except the brain and spinal cord were found to concentrate amifostine $^{15}$. In a study by Yuhas, the maximum normal tissue concentration in mice occurred between 15-30 minutes and was sustained for 90 minutes $^{14}$. The protective effect of amifostine in the salivary glands is explained by high uptake and retention of amifostine and its metabolites (thiol and disulfide) in the salivary glands ${ }^{5}$.

Several studies of patients with head and neck cancer have demonstrated the effectiveness of amifostine as both a chemoprotector and radioprotector of normal cells, without loss of antitumor efficacy in malignant cells ${ }^{5-10}$. Radiobiologic data show selective protection of normal tissues versus tumors due to differential absorption and less protection of hypoxic cells ${ }^{15}$. Therefore, the use of amifostine may allow more intensive radiochemotherapy regimens while maintaining a high response rate to treatment ${ }^{16}$. Amifostine was approved by US FDA in June 1999 for protection from xerostomia induced by postoperative radiotherapy for head and neck cancer, based on results of a randomized, controlled, multicenter trial $^{5}$. In its clinical practice guidelines, the American Society of Clinical Oncology states that the use of amifostine may be considered for reducing the incidence of acute and late xerostomia in patients receiving head and neck radiotherapy ${ }^{17,18}$.

The United States Pharmacopeia notes that amifostine may also protect mucosal tissue and may reduce the incidence of mucositis associated with radiotherapy or radiochemotherapy ${ }^{19}$. In addition to its IV use, the subcutaneous delivery of amifostine has been studied in patients with head and neck cancer treated with standard radiotherapy and is associated with an improved toxicity profile and ease of administration without the need for extensive monitoring. Early data were promising in terms of limiting mucositis and xerostomia in patients treated for $\mathrm{SCCHN}^{19}$. This study was conducted to evaluate the effect of amifostine treatment on the frequency of radiotherapy-induced mucositis in head and neck cancer patients at the Kuwait Cancer Control Center.

\section{PATIENTS AND METHODS}

The amifostine group included 35 patients of either sex that presented to the radiotherapy O.P.D. (Out Patient Department) of the Kuwait Cancer Control Center between October 2004 and May 2007 with a diagnosis of head and neck cancer. Patients with severe cardiovascular disease were excluded. Eligible patients had histologic evidence of malignancy and were investigated thoroughly to rule out metastases. Malignancies were staged according to the 1997 TNM staging system ${ }^{20}$.
Radiotherapy was administered to the primary tumor and the locoregional lymph nodes. Patients were pretreated with a fixed dose of amifostine $500 \mathrm{mg}$ in $2.5 \mathrm{~mL}$ of normal saline, given subcutaneously daily 20 minutes before radiotherapy. In those patients who received twice-daily hyperfractionated radiotherapy, the dose of amifostine was divided in two equal halves of $250 \mathrm{mg}$, administered 20 minutes prior to each radiotherapy session. Because the risk of hypotension with subcutaneous dosing of amifostine was thought to be negligible ${ }^{7,8}$, no need to stop anti-hypertensive drugs and patients continued their standard antihypertensive therapy. Antiemetics were prescribed only to those patients with persistent vomiting.

The control group consisted of 35 patients who were randomly selected from the population of patients who received radiotherapy for head and neck cancer at the Kuwait Cancer Control Center between 2000 and 2003. Staging at baseline in the control group was done according to the 1997 TNM staging system. Patients in the control group did not receive amifostine prior to radiotherapy.

Patients in each group were followed up for a minimum of 3 months. Acute toxicities (eg, mucositis, nausea/vomiting, asthenia and skin rash) during the first 3 months were graded according to the Radiotherapy Oncology Group (RTOG) 1995 scoring system. Blood pressure was measured just before and after administration of amifostine. Hypotension was defined as a drop of systolic blood pressure by $>20 \mathrm{mmHg}$ or a BP measurement $\leq 90 / 60 \mathrm{mmHg}$.

Chi-square test or Fisher's exact test for small sample size were performed to compare the frequencies of adverse events between the amifostine and control groups.

\section{RESULTS}

The baseline demographics, disease characteristics and treatment characteristics of the two groups are summarized in Table 1. The age and sex distribution of patients was comparable between the amifostine and control groups. The nasopharynx was the most common site of malignancy in both groups.

All the patients in both groups received cisplatin or carboplatin and 5-fluorouracil. Thirty patients in the amifostine group $(85.72 \%)$ received three-dimensional conformal radiotherapy (3D-CRT). Ten (28.6\%) patients in the amifostine group were treated with hyperfractionated radiotherapy (69.6 Gy in 58 fractions of 1.2 Gy given twice daily with a 6-hour gap) and the 
rest were given conventional radiotherapy (60-70 Gy in 30-35 fractions of 2 Gy each). Twenty eight patients $(80 \%)$ in the control group received three-dimensional radiotherapy. The median dose of radiotherapy in each group was 66 Gy (range, 60-70 Gy).

Mucositis of any severity was less common in the amifostine group than in the control group (71.4\% vs $97.1 \%, P=.008)$. Mucositis in the amifostine group was most commonly Grade 1 in severity; in the control group, it was most commonly Grade 2 in severity (Table 2). Nausea/vomiting was reported by $16(45.7 \%)$ patients in the amifostine group and $5(14.3 \%)$ patients in the control group $(P=.004)$ (Table 2$)$. The proportions of patients in the amifostine and control groups that experienced asthenia were also $45.7 \%$ and $14.3 \%(P=.004)$. Three $(8.6 \%)$ patients in the amifostine group and no patients in the control group had a skin $\operatorname{rash}(P=.23)$. Two of the three cases of skin rash were localized to the site of injection only. The third patient had erythematous skin rash involving trunk, abdomen, chest and face. One (2.9\%) patient in the amifostine group experienced an episode of hypotension that led to the suspension of treatment on that day only. Another patient refused amifostine therapy. There were no significant radiotherapy treatment interruptions or delays for any reason in the control group.

Table1: Baseline Demographics, Disease Characteristics and Treatment Characteristics.

\begin{tabular}{|c|c|c|c|}
\hline & $\begin{array}{c}\text { Amifostine } \\
(n=35)\end{array}$ & $\begin{array}{l}\text { Control } \\
(n=35)\end{array}$ & $P$-value \\
\hline \multicolumn{4}{|l|}{ Sex, no. (\%) } \\
\hline Male & $21(60.0)$ & $23(65.7)$ & 0.621 \\
\hline Female & $14(40.0)$ & $12(34.3)$ & \\
\hline \multicolumn{4}{|l|}{ Age } \\
\hline Mean \pm SD & $43.79 \pm 14.32$ & $45.11 \pm 12.07$ & 0.420 \\
\hline Range & $11-72$ & $12-75$ & \\
\hline \multicolumn{4}{|c|}{ Radiotherapy, no. (\%) } \\
\hline 2-Dimensional & $5(14.28)$ & $7(20 \%)$ & \\
\hline 3-Dimensional & $30(85.72)$ & $28(80 \%)$ & \\
\hline \multicolumn{4}{|c|}{ Tumor Site, no. (\%) } \\
\hline Nasopharynx & $20(57.1)$ & $23(65.7)$ & \\
\hline Oral Cavity & $6(17.1)$ & $4(11.4)$ & \\
\hline Hypopharynx & $2(5.7)$ & $4(11.4)$ & \\
\hline Oropharynx & $2(5.7)$ & $4(11.4)$ & \\
\hline Maxilla & $3(8.6)$ & $0(0)$ & \\
\hline Larynx & $1(2.9)$ & $0(0)$ & \\
\hline Base of Skull & $1(2.9)$ & $0(0)$ & \\
\hline \multicolumn{4}{|c|}{ Tumor Stage, no. (\%) } \\
\hline $\mathrm{T} 1$ & $6(17.14)$ & $3(8.57)$ & \\
\hline $\mathrm{T} 2$ & $9(25.71)$ & $10(28.57)$ & \\
\hline $\mathrm{T} 3$ & $5(14.28)$ & $7(20)$ & \\
\hline $\mathrm{T} 4$ & $15(42.85)$ & $15(42.85)$ & \\
\hline \multicolumn{4}{|l|}{ N Stage, no. (\%) } \\
\hline No & $10(28.57)$ & $5(14.28)$ & \\
\hline N1 & $5(14.28)$ & $7(20)$ & \\
\hline N2 & $14(40)$ & $13(37.14)$ & \\
\hline N3 & $4(11.42)$ & $9(25.71)$ & \\
\hline Unknown & $2(5.71)$ & $1(2.85)$ & \\
\hline
\end{tabular}


Table 2: Adverse Events.

\begin{tabular}{|c|c|c|c|}
\hline & Amifostine & Control & \\
\hline Adverse Event, No. (\%) & $(n=35)$ & $(n=35)$ & \\
\hline Mucositis & $25(71.4)$ & $34(97.1)$ & 0.003 \\
\hline Grade 1 & $11(31.4)$ & $10(28.5)$ & \\
\hline Grade 2 & $8(22.8)$ & $14(40.0)$ & \\
\hline Grade 3 & $6(17.1)$ & $10(28.5)$ & \\
\hline Nausea/Vomiting & $16(45.7)$ & $5(14.3)$ & 0.004 \\
\hline Asthenia & $16(45.7)$ & $5(14.3)$ & 0.004 \\
\hline Skin rash & $3(8.6)$ & $0(0)$ & 0.239 \\
\hline Hypotension & $1(2.9)$ & $0(0)$ & 0.313 \\
\hline
\end{tabular}

\section{DISCUSSION}

This retrospective analysis of patients who received radiochemotherapy for the treatment of head and neck cancer determined that the use of subcutaneous amifostine reduced the incidence and severity of mucositis. Of the 35 patients in each group, 10 (28.6\%) in the amifostine group had no mucositis, compared with only one $(2.9 \%)$ in the control group. Among those patients who did experience mucositis during amifostine therapy, $(71.4 \%)$ of cases were grade 1 to 2 in severity.

Grade III mucositis occurred in $17.1 \%$ of patients in the current study which is much less than $75 \%$ in the study done by Haddad et al. ${ }^{21}$ and this difference may be due to the increased toxicity associated with taxane-based chemotherapy and the use of concomitant boost radiation in Haddad et al., study. Grade III mucositis occurred in $42 \%$ of patients in the study done by Ozshain et al. ${ }^{12}$ and this is higher than $17.1 \%$ in the current study and this difference may be due to the use of concomitant boost accelerated radiation in Ozshain study ${ }^{12}$.

Side effects in this study were comparable to those reported in other studies of patients with head and neck cancer who received amifostine subcutaneously ${ }^{7,8}$. Nausea/vomiting and asthenia occurred more commonly in the amifostine group than the control group, 3 patients had cutaneous reactions, and hypotension was rare.

The first clinical trial with amifostine was performed in Japan in 1980 with a daily intravenous dose of approximately $60 \mathrm{mg} / \mathrm{m}^{2}$ administered 30 minutes before radiotherapy ${ }^{22}$. More recently, a large randomized study by Brizel et al. ${ }^{6}$ demonstrated that daily intravenous administration of amifostine successfully reduces the incidence and severity of acute and chronic xerostomia in patients with head and neck cancer who are treated with conventionally fractionated radiotherapy. In that study, patients treated with amifostine during radiation treatment suffered 31\% less chronic xerostomia than control patients. By preserving salivary gland function during radiotherapy, amifostine was found to improve daily activities and quality of life (eg, eating, talking, sleeping) $)^{23}$.

Previous studies suggested that amifostine reduces the incidence of mucositis associated with radiotherapy or radiochemotherapy ${ }^{24}$. In particular, two studies reported the efficacy and safety of subcutaneous administration of amifostine in patients with head and neck cancer ${ }^{7,8}$. Both of those studies used the same fixed dose of amifostine $500 \mathrm{mg}$ in patients who received radiotherapy without chemotherapy and demonstrated that this dose reduced the incidence of mucositis. Less evidence has been published to support the cytoprotective effects of subcutaneous amifostine during combined modality treatment with radiochemotherapy. A preliminary analysis of an ongoing Phase II trial reported that when amifostine $500 \mathrm{mg}$ was administered subcutaneously before radiotherapy in patients who also received weekly paclitaxel, higher mean doses of radiotherapy were required to elicit Grade 3/4 mucositis in the amifostine group than in the control group ${ }^{25}$. 
However, several other studies evaluated the efficacy and safety of subcutaneous amifostine during radiochemotherapy ${ }^{26-28}$. In an interim safety analysis from one of those studies, a significant proportion of patients (about $21 \%$ ) had hypotension, but $7 \%$ of patients discontinued therapy due to hypotension. The incidences of the other side effects evaluated in that study were nausea/vomiting in 39\%, local injection-site reaction in $33 \%$ and skin rashes in less than $20 \%$ of the patients ${ }^{28}$.

Although nausea/vomiting were reported more frequently in the amifostine group than the control group of this study, subcutaneous administration may mitigate this side effect of amifostine therapy. In phase II clinical trials, subcutaneous administration of amifostine was reported to reduce nausea/vomiting compared with intravenous administration ${ }^{7,8}$. Regardless of the route of administration, adequate hydration and antiemetic prophylaxis have been recommended before amifostine therapy ${ }^{30}$. Patients in this study were only given antiemetic therapy after they experienced persistent vomiting. Nausea and vomiting occurred in $45.7 \%$ in the current study and this is less than $70 \%$ in the study done by El-Ghoneimy et al. ${ }^{31}$ and this is explained by the use of intravenous administration and higher dose of amifostine $\left(740 / \mathrm{m}^{2}\right)$ in the comparable study.

Three patients had a skin rash, but in two patients it was limited to localized reactions. The third patient had a non-injection site rash.He had erythematous skin rash involving trunk, abdomen, chest and face. Amifostine was stopped as no other causative agent was noted. The rash resolved gradually with antihistaminic therapy. Severe cutaneous reactions have been reported rarely during amifostine therapy and they may be more common with subcutaneous administration than with intravenous administration of amifostine ${ }^{32}$. Therefore, the appearance of any non-injection site rash outside the radiation portal warrants withholding amifostine until an etiology for the rash can be established ${ }^{32}$.

Hypotension is an established side effect of intravenous amifostine administration, but it occurred in only one patient $(2.9 \%)$ in this study. This is comparable to the $8 \%$ rate of hypotension which occurred in patients receiving subcutaneous amifostine in the study done by Bardet et al. ${ }^{11}$

This finding supports previous reports that the risk of hypotension is minimal with subcutaneous administration of amifostine ${ }^{7,8}$.

This study suggests that subcutaneous administration of amifostine effectively reduces the severity of mucosal reactions with minimal side effects. Additional patients need to be enrolled in this study and other ongoing studies to reach definitive conclusions about subcutaneous administration of amifostine for the reduction of mucositis during radiochemotherapy for head and neck cancer.

\section{REFERENCES}

1. Shibuya K, Mathers CD, Boschi Pinto C, Lopez AD, Murray CJL. Global and regional estimates of cancer mortality and incidence by site: II. Results for the global burden of disease 2000. BMC Cancer 2002;2:Art. No. 37.

2. Vokes EE, Weichselbaum RR, Lippman SM, Hong WK. Medical progress: Head and neck cancer. N.Engl.J.Med. 1993;328(3):184-94.

3. Landis SH, Murray T, Bolden S, Wingo PA. Cancer statistics, 1999. CA Cancer J.Clin. 1999;49(1):8-31.

4. Haddad RI, Shin DM. Recent advances in head and neck cancer. N.Engl.J.Med. 2008;359(11):1143-54+1196.

5. Büntzel J, Küttner $K$, Fröhlich $D$, Glatzel $M$. Selective cytoprotection with amifostine in concurrent radiochemotherapy for head and neck cancer. Ann.Oncol. 1998;9(5):505-9.

6. Brizel DM, Wasserman TH, Henke M, Strnad V, Rudat V, Monnier A, et al. Phase III randomized trial of amifostine as a radioprotector in head and neck cancer. J.Clin.Oncol. 2000;18(19):3339-45.

7. Koukourakis MI, Kyrias G, Kakolyris S, Kouroussis C, Frangiadaki C, Giatromanolaki A, et al. Subcutaneous administration of amifostine during fractionated radiotherapy: A randomized phase II study. J.Clin.Oncol. 2000;18(11):2226-33.

8. Anneì PR. Phase II trial of subcutaneous amifostine in patients undergoing radiation therapy for head and neck cancer. Semin.Oncol. 2002;29(6 Suppl. 19):80-3.

9. Büntzel J, Glatzel M, Kuttner K, Weinaug R, Fröhlich D. Amifostine in simultaneous radiochemotherapy of advanced head and neck cancer. Semin.Radiat.Oncol. 2002;12(1 Suppl. 1):4-13.

10. Antonadou D, Pepelassi M, Synodinou M, Puglisi M, Throuvalas N. Prophylactic use of amifostine to prevent radiochemotherapy-induced mucositis and xerostomia in head-and-neck cancer. Int.J.Radiat.Oncol.Biol.Phys. 2002;52(3):739-47.

11. Bardet E, Martin L, Calais G, Alfonsi M, Feham NE, Tuchais C, et al. Subcutaneous compared with intravenous administration of amifostine in patients with head and neck cancer receiving radiotherapy: Final results of the GORTEC 2000-02 phase III randomized trial. J.Clin. Oncol. 2011;29(2):127-33.

12. Ozsahin M, Betz M, Matzinger O, Bron L, Luthi F, Pasche $\mathrm{P}$, et al. Feasibility and efficacy of subcutaneous amifostine therapy in patients with head and neck cancer treated with curative accelerated concomitant-boost radiation therapy. Arch.Otolaryngol. Head Neck Surg. 2006;132(2):141-5. 
13. Eisbruch A. Amifostine in the treatment of head and neck cancer: Intravenous administration, subcutaneous administration or none of the above. J.Clin.Oncol. 2011;29(2):119-21.

14. Yuhas JM. Active versus passive absorption kinetics as the basis for selective protection of normal tissues by S-2(3-aminopropylamino)-ethylphosphorothioic acid. Cancer Res. 1980;40(5):1519-24.

15. Perez CA, Brady LW. Principles and practice of radiation oncology. 3rd ed. Lippincott Williams \& Wilkins; 1998.

16. Bourhis J, Rosine D. Radioprotective effect of amifostine in patients with head and neck squamous cell carcinoma. Semin.Oncol. 2002;29(6 Suppl. 19):61-2.

17. Hensley ML, Schuchter LM, Lindley C, Meropol NJ, Cohen GI, Broder G, et al. American society of clinical oncology clinical practice guidelines for the use of chemotherapy and radiotherapy protectants. J.Clin.Oncol. 1999;17(10):3333-55.

18. Schuchter LM, Hensley ML, Meropol NJ, Winer EP. 2002 Update of recommendations for the use of chemotherapy and radiotherapy protectants: Clinical practice guidelines of the american society of clinical oncology. J.Clin.Oncol. 2002;20(12):2895-903.

19. Anné PR, Machtay M, Rosenthal DI, Brizel DM, Morrison WH, Irwin DH, et al. A Phase II trial of subcutaneous amifostine and radiation therapy in patients with head-and-neck cancer. Int.J.Radiat.Oncol.Biol.Phys. 2007;67(2):445-52.

20. Sobin LH, Fleming ID. TNM classification of malignant tumors. 5th ed. New York, NY: Wiley-Liss; 1997.

21. Haddad R, Sonis S, Posner M, Wirth L, Costello R, Braschayko $\mathrm{P}$, et al. Randomized phase 2 study of concomitant chemoradiotherapy using weekly carboplatin/ paclitaxel with or without daily subcutaneous amifostine in patients with locally advanced head and neck cancer. Cancer 2009;115(19):4514-23.

22. Brady LW. Clinical experiences of chemical radiation protection in tumour radiotherapy in Japan. Radiation sensitizers. New York: Masson; 1980. p. 421.
23. Wasserman T, Mackowiak JI, Brizel DM, Oster W, Zhang J, Peeples PJ, et al. Effect of amifostine on patient assessed clinical benefit in irradiated head and neck cancer. Int.J.Radiat.Oncol.Biol.Phys. 2000;48(4):1035-9.

24. Komaki R, Lee JS, Milas L, Lee HK, Fossella FV, Herbst RS, et al. Effects of amifostine on acute toxicity from concurrent chemotherapy and radiotherapy for inoperable non-small-cell lung cancer: Report of a randomized comparative trial. Int.J.Radiat.Oncol.Biol. Phys. 2004;58(5):1369-77.

25. Braaksma M, Levendag P. Tools for optimal tissue sparing in concomitant chemoradiation of advanced head and neck cancer: Subcutaneous amifostine and computed tomography-based target delineation. Semin.Oncol. 2002;29(6 Suppl. 19):63-70.

26. Nabell L, Spencer S. Docetaxel with concurrent radiotherapy in head and neck cancer. Semin.Oncol. 2003;30(6 Suppl. 18):89-93.

27. Haddad R, Wirth L, Costello R, Weeks L, Posner M. Phase II randomized study of concomitant chemoradiation using weekly carboplatin/paclitaxel with or without daily subcutaneous amifostine in patients with newly diagnosed locally advanced squamous cell carcinoma of the head and neck. Semin.Oncol. 2003;30(6 Suppl. 18):84-8.

28. Samuels MA, Chico IM, Fullmer K, Hirsch RL. Ongoing prospective multi-center safety study of subcutaneous cytoprotectant amifostine. Int.J.Radiat.Oncol. 2003 Oct;57(2 Suppl.):S224.

29. Boccia R. Improved tolerability of amifostine with rapid infusion and optimal patient preparation. Semin.Oncol. 2002;29(6 Suppl. 19):9-13.

30. El Ghoneimy E, Gaber MH, El Din ES. Ethyol as a nephrochemoprotector for cancer patients receiving cisplatinum base chemotherapy. Cairo University; 1999.

31. Boccia R, Anné PR, Bourhis J, Brizel D, Daly C, Holloway III $\mathrm{N}$, et al. Assessment and management of cutaneous reactions with amifostine administration: Findings of the Ethyol (amifostine) Cutaneous Treatment Advisory Panel (ECTAP). Int.J.Radiat.Oncol.Biol.Phys. 2004;60(1):302-9. 
